\title{
MESA 3: AÇÕES AFIRMATIVAS NA UFRGS
}

HELENA FIETZ ${ }^{1}$

UFRGS

VALÉRIA AYDOS ${ }^{2}$

UFRGS

A sensação que tivemos assim que chegamos para o segundo dia do evento Ações afirmativas no PPGAS/UFRGS: diálogos com experiências de inclusão e permanência de estudantes indígenas, negros e de pessoas com deficiência na Universidade brasileira era de que as falas acaloradas e as trocas de experiências pessoais do dia anterior não haviam contado com uma noite de sono. Os pequenos grupos de pessoas que aos poucos se aglomeravam nos corredores do prédio do Instituto Latino-Americno de Estudos Avançados (ILEA), enquanto sorviam um café forte, trocavam contatos e impressões emocionadas sobre os caminhos já percorridos nos cursos de pós-graduação em Ciências Humanas no Brasil e o quanto ainda deve ser feito para uma real implementação e valorização das políticas afirmativas no ensino superior brasileiro.

Os debates sobre a necessidade de encararmos de frente a urgência de transformação dos pós-graduações em espaços mais acessíveis, justos e inclusivos ganhavam "carne e osso" nos relatos de professoresorientadores e de alunos de pós-graduação. As experiências pessoais,

\footnotetext{
${ }^{1}$ Possui Graduação em Ciências Jurídicas e Sociais - Direito pela Pontifícia Universidade Católica do Rio Grande do Sul (2008). Mestranda em Antropologia Social pela Universidade Federal do Rio Grande do Sul. Atualmente é pesquisadora vinculada ao Núcleo de Antropologia e Cidadania (NACi), e ao Grupo de Pesquisa Ciências na Vida: Produção de conhecimento e articulações heterogêneas. E-mail: helenafietz@gmail.com.

${ }^{2}$ Bacharel em Ciências Sociais pela Universidade Federal do Rio Grande do Sul. Mestre e doutoranda em Antropologia Social pela mesma universidade. E-mail: valeria.aydos@gmail.com .
} 
que nos foram generosa e corajosamente relatadas durante todo o evento, desestabilizaram concepções ainda meritocráticas e normativas dos participantes ao escancararem não apenas as nossas deficiências institucionais em garantir um acesso justo e a permanência de alunos negros, indígenas e com deficiência nestes espaços, mas também ao denunciarem o quanto, mesmo dentro da Antropologia, disciplina que teria a alteridade como "objeto de estudo", ainda não encaramos na vida acadêmica a diversidade como um valor. Esta preocupação consubstancializou-se nas diversas vozes que compunham as mesas deste evento, tecendo, a cada nova perspectiva, a complexidade do trabalho que ali começava. Nas palavras do professor José Carlos dos Anjos, precisamos, antes de tudo, "assumir que nossos programas e institutos estão largamente despreparados para receber alunos oriundos de ações afirmativas". A partir deste pressuposto, então, poderemos dar início, interdisciplinarmente, a uma real implementação das políticas de cotas nos pós-graduações.

Este segundo dia do evento foi organizado em uma mesa, com duas partes, de reflexões sobre o estado da arte das políticas afirmativas em cursos de pós-graduação da Universidade Federal do Rio Grande do Sul (UFRGS) e relatos de experiências institucionais de funcionários administrativos, docentes e discentes da Universidade. A primeira mesa, coordenada pela professora Ceres Víctora, contou com a presença de Karen Bruck (da Coordenadoria de Acompanhamento do Programa de Ações Afirmativas - CAF/UFRGS), José Rivair (professor do PPG em História), Danilo Braga (kaigang, mestre pelo PPG em História), Maria Aparecida Bergamaschi (professora do PPG em Educação), Zaqueu Claudino (kaigang, mestre pelo PPG em Educação) e Bruno Ferreira (kaigang, mestre pelo PPG em Educação). No segundo momento a mesa, também coordenada pela professora Ceres, foi composta por José Carlos dos Anjos (professor do PPG em Sociologia), Liliana Passerino (professora do PPG em Educação), Felipe Mianes (pessoa cega, mestre e doutor pelo PPG em Educação da UFRGS e pós-doutorando na ULBRA) e Marcus Morais (pessoa cega, mestre pelo PPG em Educação). 


\section{1 a Parte: "O mais difícil de manter um aluno indígena no pós-graduação é mantê-lo como indígena" (Bruno Ferreira, historiador, mestre em Educação - UFRGS)}

As falas desta primeira mesa do dia poderiam ser sintetizadas na frase de Bruno Ferreira, escolhida para intitular os desafios políticos, pedagógicos e epistemológicos a serem enfrentados na implementação de cotas nos pós-graduações.

Karen Bruck, responsável pela Coordenadoria de Acompanhamento do Programa de Ações Afirmativas (CAF) da UFRGS33, inicia sua participação nesta mesa tomando-nos de surpresa com um trecho da fala de José Luís Zuniga Mendonça, estudante indígena do Programa Erasmus Mundus do Brasil, em Portugal. No vídeo sobre sua experiência em outro país, José Luís explica o que entende por "diversidade" a partir de metáforas das cores e linhas de suas mãos, e sintetiza sua experiência ao dizer que está em Portugal "cumprindo sua profecia".

A compreensão "coletiva" de sujeito que marca sua fala foi reforçada pelos outros participantes kaingang da mesa ao reforçarem a ideia de que não são "indivíduos indígenas" que estão cursando o pósgraduação. Eles, lá, são os coletivos dos quais fazem parte, eles são sua família, sua comunidade.

Após o vídeo, Karen nos conta sobre os desdobramentos desta experiência do indígena: diz que José Luís descobriu, ao longo de sua trajetória na faculdade de Ciências Sociais e no estágio no exterior, que "a universidade não servia para ele". "Luís nos contou que estudou também para descobrir o que ele não queria saber", diz Karen. "José Luís hoje largou a universidade e, provavelmente, não vai voltar", lamenta Karen. "Hoje ele viaja o mundo disseminando seus conhecimentos de xamã".

Para Karen, o vídeo contava não apenas uma história de choque cultural, mas evidenciava o espaço ainda homogêneo que é a universidade. A UFRGS é a única universidade que tem uma Coordenadoria de Acompanhamento do Programa de Ações Afirmativas

\footnotetext{
${ }^{3}$ A Coordenadoria de Acompanhamento do Programa de Ações Afirmativas, instituída em 2012, é um órgão específico da Universidade responsável pelo acompanhamento do Programa de Ações Afirmativas da Universidade. Maiores informações disponíveis em: 〈http://www.ufrgs.br/acoesafirmativas〉.
} 
(CAF), um órgão de gestão específico, responsável pela gestão, monitoria, relatoria e elaboração de sugestões no acompanhamento do programa de ações afirmativas mais amplo da Universidade. Segundo Karen, "isso significa muito, pois, diferentemente de outras universidades que buscam dar conta das ações afirmativas somente com um grupo de trabalho ou um fórum de discussão, na UFRGS esta questão ganha um status privilegiado, além de contar um espaço físico que acolhe os alunos, os professores e uma equipe específica para a gestão do programa de ações afirmativas na instituição", o que lembra Karen, "já devia ser conhecido por todos".

Nesta fala, fomos ainda informados de que a Região Sul está fomentando um fórum do programa de ações afirmativas para debates em torno desta questão. O vídeo foi provocativo porque mostra o programa de mobilidade acadêmica da UFRGS, o qual em discussão com a Comunidade Europeia, conta com uma categoria de alunos em vulnerabilidade na qual estão incluídas vagas para alunos optantes pelas cotas indígenas e negros. A trajetória de José Luís, comenta Karen, "nos diz muito sobre o desafio do que é trabalhar com alunos diferentes. A diversidade ainda não é um valor, ela ainda atrapalha, incomoda e nem de perto é um valor como deveria".

Karen encerra sua fala contando sua experiência pessoal de "vivência da diversidade na carne", quando participou em uma atividade de cooperação junto ao Museu da UFRGS na qual, anualmente, no mês de abril, funcionários, professores e alunos são convidados a vivenciarem um dia em uma aldeia mbyá-guarani próxima da cidade:

Eu queria compartilhar com vocês a sensação que eu tive nesta atividade de capacitação para a alteridade. A minha situação foi de desconforto. A falta de etiqueta, de não saber como me portar... A língua é diferente, o tempo é diferente, tudo é diferente... E por um momento eu tive um insight: Puxa vida! Eu tô aqui porque eu quero, vou ficar aqui um tempo e depois eu vou embora. Imaginem os alunos indígenas que encaram vir para um lugar que não é o deles, ficar aqui por 4 anos, longe da família, dos amigos, da comunidade, longe da sua língua... Acho que isso mostra o que significa acolher a diversidade aqui nos muros da Universidade. É isso. 
O próximo a contribuir com a mesa foi o prof. Dr. José Rivair, do Programa de Pós-Graduação em História da Universidade Federal do Rio Grande do Sul.

Um primeiro ponto mencionado pelo professor diz respeito às dificuldades objetivas a serem enfrentadas na implementação do programa de cotas no pós-graduação em História. Reclama a importância de discutirmos a valorização da diversidade intelectual dentro dos programas. Ele foi o primeiro professor do curso de História da UFRGS a orientar um pós-graduando negro - o hoje prof. Dr. Hilton Costa, que atua no Núcleo de Estudos Afro-Brasileitos da Universidade Federal do Paraná (NEAB/UFPR). Segundo o prof. Rivair, "se ele não aceitasse orientar o Nilton, provavelmente ele não teria feito um pós-graduação". Primeiro porque não havia um professor que trabalhasse com o tema proposto por Nilton, incluindo Rivair, que trabalhava com estudos medievais na época); e, segundo, porque havia um conhecimento já estabelecido do que seria fazer um estudo sobre movimentos sociais, e o prof. Hilton trazia outras referências e uma forma diferente de fazer pesquisa.

Rivair lamenta a falta de sensibilidade a temas cuja expertise não existe e reforça que faz-se necessário avaliarmos o que ele chama de um "racismo epistemológico", o qual apregoa o que é considerado conhecimento, o que é saber... "Temos que discutir o que é pesquisa e que referências e formas de fazer pesquisa os estudantes de pósgraduação negros ou indígenas podem trazer para os programas como contribuição positiva", diz o professor.

A fala de Rivair ressalta, ainda, a importância política da presença dos negros e indígenas dentro dos pós-graduações, no sentido de um empoderamento destas pessoas e suas comunidades no momento que estamos vivendo. O professor comenta da sua felicidade em ver que este debate está sendo realizado com apoio da coordenação em seu pósgraduação, com a participação dos alunos, e espera que já no próximo processo seletivo da UFRGS conte com um programa de cotas.

Após a manifestação do prof. Rivair, contamos com o relato da experiência de um ex-aluno de mestrado do PPGHist, Danilo Braga. Danilo leciona a língua kaingang na escola de sua aldeia e também assume as aulas de história. A dissertação de Danilo, exemplo da diversidade epistemológica que mencionou o prof. Rivair, conta com um 
memorial de sua experiência de vida, e é esta trajetória que ele nos conta em sua fala.

Danilo começa agradecendo a oportunidade de poder falar sobre suas experiências, o que tem feito desde 1995 quando chegou à Universidade Regional do Noroeste do Estado do Rio Grande do Sul Unijuí, e também de poder dizer "Nós estamos aqui". Nesta frase, Danilo enfatiza a presença indígena não apenas no evento ou na universidade, mas no Sul do Brasil!

Inicia a narrativa de sua história dizendo que precisa dizer isso, "porque muita gente, às vezes até os parentes, os Xavante, os Caiapó já nos chamam de 'alemão'... Pensam que no sul não tem mais índio". Conta em um tom cômico, que em São Paulo, onde foi apresentar um trabalho, "um parente lá disse que na cidade dele tem um prefeito, que é de Passo Fundo, e que havia Ihe dito que no Sul não tem mais índio!".

Danilo deixa a entender que estudar não era o objetivo de sua família. Que "acabou indo estudar por conta de uma cirurgia no coração, que fez com que seu pai não o escalasse para o time de futebol", atividade de que tanto gostava. Em resposta ao pai, fez vestibular para Educação Física. Danilo se considera fruto do projeto de branqueamento da raça nas aldeias. Foi criado pela avó paterna, considerada "branca" na aldeia. Sua avó foi a única de nove irmãos que ficou na aldeia, casou com um índio, um Braga - que são famosos na resistência indígena na história do Rio Grande do Sul no século XIX.

Este ano, 2015, é que estão começando a ter o ensino médio nas aldeias. A trajetória escolar dos índios até 2001 ia até a $4^{a}$ série. Então, segundo Danilo, "quem estudava até a $4^{a}$ série tava ótimo". "A trajetória de quem seguia os estudos era essa: até o $4^{\circ}$ ano na aldeia e depois já vinha a expectativa: vou andar de ônibus, vou pra escola na cidade. Quem ia estudar fora da aldeia tinha bolsa da Funai e a gente ficava nessa ansiedade de ter a bolsa. Mas quando eu cheguei e quando fui estudar a Funai cortou as bolsas". No ensino médio Danilo também sofreu com os cortes nas bolsas, sendo que a Funai pagou somente os livros e uniformes. Quem custeou seus estudos então foi a avó materna que morava no Ruben Berta. Ela Ihe disse: "Ó, já que tu não presta mais pra roça, não pode mais trabalhar, tu vem aqui que a vó faz os artesanato e 
te dá dinheiro pros estudos". De uma turma de 25 alunos, só 2 concluíram o ensino médio. Um era ele.

Danilo fala que "depois do ensino médio a gurizada ia colher maçã. Era divertido, todo mundo queria ir. Vou pras maçã, eu pensei! Pra nós era grande coisa isso aí... E fiquei um ano lá na expectativa se podia ir pra universidade, e fui".

Danilo estudou na Unijuí porque esta universidade ofereceu uma bolsa que custeava $50 \%$ das mensalidades e, a partir da criação de uma associação, conseguiram com a Unijuí e o Comin bolsas da Alemanha. E foi com uma das quinze bolsas de 250 dólares advindas da Alemanha que conseguiu custear os estudos. "E agente torcia pro dólar subir... E hoje fico vendo as notícias que o dólar chegou a quatro reais... Tava rico!", brinca Danilo.

Danilo foi o primeiro kaingang a cursar um pós-graduação na faculdade de ciências humanas no Rio Grande do Sul. Uma questão importante de ser ressaltada no relato de Danilo é que ele menciona que, como já tinha bolsa da Fundação Ford, não precisou passar pelo processo seletivo no mestrado. Fez a entrevista e, no fim do curso, a prova de proficiência em inglês. Mas a vida acadêmica para muitos indígenas não traz apenas as questões estudantis e financeiras, Danilo foi chamado a ser vice-cacique de sua aldeia, papel que não pôde negar, e foi só mudando-se de aldeia e conseguindo isolar-se por um tempo das atribuições que lhe cabiam que conseguiu finalizar seus estudos. "Me fechei num galpão na aldeia do meu irmão e disse: 'Agora eu me isolo aqui e ninguém me atrapalha'. E terminei as 50 páginas que ainda precisava em 7 dias", conta ele.

O dia a dia de Danilo no pós-graduação era um misto de orgulho e diciculdades. Conta que "quando caminhava pelos corredores da UFRGS, pensava: 'Nossa, eu tô na UFRGS'... Nos meus pensamentos eu estava lá em cima". "Mas em sala de aula não foi fácil", compartilha. Algumas disciplinas não faziam sentido para ele, "a língua inglesa não entrava em sua cabeça". Agora Danilo pensa em fazer doutorado, mas perdeu a última seleção da UFRGS por não ter conseguido anexar sua dissertação de mestrado no sistema para gerar o boleto e, em Santa Catarina, onde tinha tido seu projeto muito bem avaliado, não teve condições financeiras para ir fazer a prova. Estas questões pragmáticas, tão simples para tantas 
pessoas, são barreiras difíceis de serem transpostas por alunos indígenas como Danilo.

As próximas falas, da prof. $^{\text {a }}$ Maria Aparecida Bergamaschi, conhecida como prof. ${ }^{a}$ Cida, e de seus ex-orientandos, Zaqueu Claudino e Bruno Ferreira, trouxeram um pouco da experiência do Programa de Pós-Graduação em Educação (PPGEdu) da UFRGS com alunos indígenas. A prof. ${ }^{a}$ Cida conta como o Programa vem lidando com o acolhimento destes alunos e informa que o PPGEdu já instituiu uma comissão para implementar uma política de ações afirmativas no pós-graduação. "Talvez a força do PPGEdu venha do fato de ser um programa muito plural”, diz Cida, e ressalta que "já nos anos 1980 já havia estudantes negros no pósgraduação. A professora Petronilha Gonçalves, que é uma grande intelectual negra do Brasil e do mundo, fez doutorado na Educação". Lembra que a ida de alguns professores ao exterior, como o orientador da prof. ${ }^{a}$ Petronilha, o prof. Alceu Ferraro, pode ter impulsionado essa perspectiva plural do programa e sua postura de acolhimento.

O PPGEdu teve o ingresso de 4 estudantes indígenas. Dois que estão aqui hoje e irão relatar suas experiências e mais dois que estão no mestrado. Quanto ao processo seletivo, a professora explica que, assim como o Danilo Braga, o Zaqueu teve seu ingresso sem exigência de provas, pois já havia passado pelo processo seletivo da bolsa Ford, que é bastante exigente. Já os outros alunos que participaram do processo seletivo, ambos tiveram bolsa porque na Educação há uma avaliação social na concessão das bolsas e os estudantes indígenas entram como prioridade.

A professora Maria Aparecida enfatiza que a língua estrangeira é um desafio para estes alunos, que contam com a ajuda de colegas para conseguirem passar na proficiência. Mas com relação ao acolhimento, fora a insuficiência do valor das bolsas para estes alunos que têm família, o que faz com que tenham que contar com o Comin ou outras instituições, por exemplo, a incompreensão epistemológica ainda é um fato que gera exclusão, principalmente dos indígenas, no pós-graduação. Há que se dizer que há uma incompreensão e uma desvalorização de conhecimentos originários por parte do programa como um todo. Neste sentido, o acolhimento é bastante individualizado na relação orientadororientando. 
A prof. ${ }^{a}$ Cida relata que, "em geral, temos visto que os estudantes indígenas chegam bastante assustados com essa cultura academicista que a Universidade impõe e levam um tempo para se acomodarem, encontrarem suas parcerias e conseguirem ver a possibilidade de trazerem seus conhecimentos para dentro da Universidade". Esta sabedoria diferente eles já estão mostrando, segundo a professora, em uma metodologia própria - na vida como conhecimento e na postura de campo na aldeia como kaingang para fazerem suas pesquisas junto aos mais velhos - e "um outro tipo de escrita, uma escrita desocidentada, uma escrita em que a vida conta, a terra conta, o coração conta... Uma escrita que traz muita emocionalidade", diz a professora. Para Maria Aparecida, "esta postura colaborativa que estamos tendo junto a eles tem sido um grande aprendizado intercultural que estes estudantes estão trazendo".

Os dois últimos palestrantes da mesa foram Zaqueu Claudino e Bruno Ferreira, ambos mestres em Educação.

Zaqueu Claudino é kaingang e mestre pelo PPGEdu. Atualmente é diretor de uma escola indígena e coordenador técnico do Ensino Médio Politécnico à noite. Sua trajetória marca uma resposta aos desafios de ser indígena no nosso sistema educacional. Zaqueu conta que buscou sua formação para mostrar a uma pessoa que havia lhe dito, quando ela monitor em uma escola, que "ele não tinha competência para estar ali como professor". Sente-se orgulhoso em ter encontrado essa pessoa quando já era "mestre pela UFRGS" e ter podido mostrar o resultado de seus esforços.

A fala de Zaqueu trouxe à plateia do evento uma materialidade que fez com que conseguíssemos compreender um pouco sobre o que seria ser um indígena na academia. A forma com que conta ter conseguido "aprender" os conhecimentos trazidos pelo pós-graduação em Educação nos faz pensar sobre as temporalidades diferentes destes alunos... Zaqueu conta que levou tempo para aprender os saberes "científicos" e para entender que "os professores eram os pajés aqui". Ele tenta nos explicar que para entender as teorias da Educação, precisou buscar um suporte na oralidade tradicional e, a partir dali, traduzir os conhecimentos da academia na sua língua e depois traduzir para o português. "Nós na aldeia aprendemos pela oralidade em volta do fogo, em contato com a 
mãe terra. Precisamos deitar na terra para absorver este conhecimento. Aqui é diferente..."

Zaqueu ressalta que sem o acolhimento de alguns professores não teria conseguido fazer um pós-graduação e reforça o já dito por outros palestrantes, que a política institucional de acolhimento é o essencial para a permanência dos alunos indígenas. Lembra que um dia falou para um professor seu da graduação, que duvidava de seu desempenho, que um dia iria fazer um pós-graduação. Diz que esse professor Ihe disse: "Você não vai conseguir chegar lá". Ao que ele respondeu: "Eu espero que o senhor esteja vivo para eu poder lhe convidar para a defesa". "Infelizmente não foi possível convidá-lo", lamenta Zaqueu. "Essas pessoas fazem a gente falar o que não quer!". A intervenção cômica de Zaqueu seria engraçada se não refletisse a postura avessa à diversidade da academia, com seus critérios autocentrados do que é competência, conhecimento e mérito...

A dissertação de mestrado de Zaqueu propõe uma desconstrução da ocidentalização da escola indígena, uma "kainganização da escola indígena", e mostra várias estruturas da escola branca na aldeia que fere os valores e a cultura de seu povo. "Queremos conhecimentos que tenham a ver com a realidade da comunidade, um calendário escolar que tenha a ver com a comunidade", diz Zaqueu. Sua dissertação, orientada pela professora Maria Aparecida, tem vários capítulos pequenos, escritos em um tempo da oralidade e para sua banca, o cacique de sua comunidade foi convidado a falar junto aos professores do pós-graduação. O trabalho de Zaqueu é para que as crianças indígenas não saiam das aldeias, que se formem e voltem para suas terras. Se orgulha hoje de ser diretor da escola nas terras da Guarita, onde seu avô nasceu. "Nós não estudamos para cultuar outra cultura. Estamos sempre com um pé na aldeia e um pé na universidade. Nós intelectuais indígenas estamos deixando de ser cobaias para sermos pesquisadores indígenas e assumirmos os nossos espaços".

O próximo a compartilhar sua trajetória foi Bruno Ferreira. Ele é kaingang, historiador, mestre pelo PPGEdu e hoje trabalha em um instituto de educação indígena como coordenador pedagógico e professor de História da Educação, História e Direito Indígena. A fala afetiva de Bruno ao nos contar sua trajetória afetou a todos. A plateia se 
viu literalmente em uma roda de causos enquanto Bruno falava de sua infância, quando foi criado pela avó, e sobre sua chegada na "escola dos brancos" no $5^{\circ}$ ano, quando falava apenas a língua kaingang. "Foi esse $o$ motivo maior, eu acho, que faz eu estar aqui", reflete Bruno, "por ter sido castigado para falar português. A professora batia na gente para falar português".

Bruno nos conta um pouco sobre sua experiência escolar:

$\mathrm{Na}$ escola não sei como fui passando de ano, porque eu mal falava e não lia português. Um dia, meu pai, que é analfabeto, comprou um livro que a professora pediu que se chamava Aprenda sozinho. Aí a gente tinha que fazer a leitura do livro. E eu vi que ela começava a cobrar a leitura pelo aluno da frente da esquerda da sala. Aí eu sentava no fundo da aula, na direita - e era o último a ter que ler o texto. Eu ia escutando as leituras e, quando chegava minha vez, eu já tinha decorado todas as palavras, e contava a leitura dos colegas palavra por palavra. Mas um dia eu esqueci uma palavra e a professor me deixou de castigo [...]. Aí, no quinto ano, quando tinhamos um monte de matérias, eu ainda não sabia escrever. As professoras ditavam as matérias e eu fingia que escrevia, ficava riscando no caderno e a professora confiante que eu estava escrevendo... Nesse ano eu passei em inglês, que não reprovava, e religião. Um dia a professora de História, que chamava Marisa, me passou em História na recuperação. Ela percebeu que eu não escrevia nada e começou a fazer prova oral comigo. Todo mundo fazia prova e eu não fazia, entregava em branco pra ela. Aí, depois da aula, ela me chamava lá na frente e ela me fazia as perguntas. Eu ouvia toda aula dela e eu sabia as perguntas... Foi isso que me fez hoje estar aqui, pelo reconhecimento da nossa língua indígena que nos foi negado. [...] No ensino Médio reprovei três anos. Quando chegava em setembro eu desistia, porque tinha que marchar. Eu não aceitava isso e desistia. Aí no quarto ano eu ia rodar de novo... e tinha uma professora de Matemática. Ela viu que eu ia rodar. Aí ela me disse pra eu colar!

Estas atitudes individuais de compreensão por parte das professoras de Bruno foram recorrentes também nas experiências universitárias narradas ao longo do evento. Apesar de serem histórias comoventes, os participantes enfatizam que o ter que contar com a 
empatia ou a boa vontade de professores e colegas não deve ser a regra. O que estas experiências chamam a atenção é para necessidade de uma política institucional de acolhimento destas pessoas.

A trajetória de Bruno na faculdade de História na Unijuí, possibilitada pela ação de lideranças indígenas e por uma bolsa da Alemanha já mencionada por outros colegas, não foi muito diferente de sua vida escolar. Bruno decorou livros contados oralmente pelos colegas e também sofreu preconceitos e estigmatizações por ser indígena. Um dia, ao apresentar "melhor que os colegas o livro Veias Abertas da América Latina", escutou de um colega: "Mas tu não é mais índio. Tá falando ainda aí do livro... E tu usa roupas, né!?" Ao ouvir aquilo, Bruno comenta que a vontade era de dizer: "Bom, vou tirar minhas roupas, então!". "É difícil porque aqui na Universidade as pessoas não respeitam a gente como a gente é. Ou você é como eles são, ou você não é nada. É um esforço muito grande", diz Bruno. Bruno brinca que, quando foi para Universidade Estadual de Campinas (Unicamp) por um semestre como aluno especial, seus olhos puxados fizeram com que ficasse conhecido como "Japa".

Quando eu era Japa, era interessante porque as pessoas me aceitavam, gostavam de $\operatorname{mim} . .$. Tinha até uma menina, uma oriental, que queria namorar comigo. Eu tinha muitos amigos, ia na Universidade, ia na biblioteca e ficava lá fazendo de conta que estudava, né... Mas um dia contaram que eu era indígena. Aí perdi meus amigos. Era privilegiado na hora do almoço porque sempre tinha um banco só pra mim, ninguém sentava lá no meu lado. Aí eu ia fazer caminhada no parque da lagoa e eu entrava no grupo... e o grupo ia se desfazendo... Não era ingenuidade minha. Eu queria ver até que ponto os não indígenas eram capazes de conviver comigo. Era engraçado lá... Um dia a gente foi na farmácia, que as atendentes são tudo bonita, eu e outro amigo indígena que sustentava nós dois com a bolsa da Fundação Ford dele, e a moça nos perguntou: Vocês são o quê? A gente olhou pra ela e disse: "Nós somos gente".

Na Unicamp não aprovaram o projeto de Bruno, que propunha questionar a formação dos professores. Seu projeto foi aceito no PPGEdu, onde ingressou sob orientação da professora Cida. Bruno conta que na seleção perguntaram-Ihe: "Se tu não ganhar a bolsa, como tu vai fazer?" 
Ao que ele respondeu: "Professor, o senhor não se preocupa com isso... Eu quero é passar na seleção. Se eu não tiver a bolsa, eu vi um monte de pessoas dormindo ali debaixo das pontes, eu vou dormir ali".

A convivência de Bruno na cidade foi muito dolorida. Via que os jovens não respeitavam os mais velhos e outras tantas coisas com as quais ele não conseguia conviver. "Eu não queria ser que nem eles", diz Bruno. Os colegas não o respeitavam. Diziam que ele havia entrado no pós "porque era índio", ouviu até que "o lugar dele era no mato". Bruno diz não ter sido fácil e ressalta: "O mais difícil de manter um aluno indígena é manter ele como indígena. É muito difícil sobreviver numa universidade onde você tem trezentos livros para ler em uma noite... você não tem nem tempo pra pensar sobre o que leu". E finaliza sua reflexão dizendo que os indígenas tem voz, sempre tiveram, o que eles precisam é do ouvido das pessoas.

Os relatos dos colegas kaingang colocaram em evidência questões que podem ser generalizáveis a muitos alunos. No entanto, queríamos ressaltar nesta relatoria que muitas das dificuldades e desafios compartilhados pelos professores e estudantes de pós-graduação, apesar de serem passíveis de generalização a outros alunos de baixa renda ou com formas diferentes de encarar o mundo e o trabalho, viamse potencializadas nas trajetórias dos alunos ali presentes, marcadas pelo racismo, pela exclusão e pelo desrespeito às suas especificidades culturais.

As falas da mesa nos levam a refletir sobre os critérios eliminatórios dos processos de seleção, calcados em saberes que privilegiam escolas teóricas ou ferramentas específicas, como o domínio de línguas estrangeiras hegemônicas na academia. Especificamente sobre os processos seletivos, o debate evidenciou que tensionar alguns critérios não nos levaria a deslegitimar a compreensão da necessidade de conhecermos as diferentes correntes da Antropologia ou o conhecimento de línguas estrangeiras hegemônicas com as quais nos comunicarmos com o mundo, mas sim relativizar alguns saberes.

Em termos mais propositivos, podemos, por exemplo, refletir sobre qual seria a língua estrangeira importante ou necessária de os alunos dominarem para cada corrente epistemológica e área de pesquisa a qual estão se candidatando e, também, questionarmos o fato de este saber ser 
eliminatório em um processo seletivo. Além disso, o que se evidenciou nas falas principalmente dos alunos indígenas foi que se realmente tivéssemos a diversidade como um valor, levaríamos em consideração o fato de que estes alunos já dominam mais de uma língua: a do seu povo e a língua portuguesa, e, também, a ciência de que seus temas de pesquisa podem exigir que eles dominem não o inglês e o francês, mas sim o espanhol, por exemplo, para terem acesso à literatura que thes interessa.

\section{2a Parte: "Nada sobre nós sem nós"}

A segunda mesa da manhã, apresentada pela Dra. Ceres Victora, professora do PPGAS/UFRGS, teve início com a fala de Dr. José Carlos dos Anjos, professor do PPG em Sociologia/UFRGS, cujo teor mais abrangente e propositivo sintetizou muitas das propostas antes apontadas e deu o tom para as discussões que o seguiram.

Embora mais voltadas para a inclusão de pessoas com deficiência no corpo discente dos programas de pós-graduação, os relatos desta mesa compartilham preocupações e propostas semelhantes com as destacadas pelo professor José Carlos dos Anjos. Em sua fala, José Carlos destacou que, mais do que possibilitar o ingresso dos alunos optantes, são necessárias medidas efetivas para que a presença e retenção destes pós-graduandos sejam possibilitadas por meio de um reconhecimento e valorização das diferenças no espaço acadêmico. Além disso, o professor trouxe uma questão que nos parece ser central para a discussão: se tratado seriamente, o desafio das ações afirmativas pode transformar os programas para todos os alunos, uma vez que várias dessas dimensões são alargáveis e generalizáveis para todas as relações professor-aluno.

Desde o princípio, ele tocou em um ponto nefrálgico da discussão que havia pairado no ar durante os dois dias do evento, porém sem ser abordado diretamente: "É preciso termos a humildade para reconhecer que os nossos institutos estão largamente despreparados para receber os alunos oriundos das ações afirmativas e, mais ainda, para mantê-los". A partir deste reconhecimento é que seria possível começar a trabalhar a questão das ações afirmativas, um trabalho que deves ser feito a longo 
prazo. Em torno disso, passou a tecer 5 proposições, as quais afirmou não serem ainda exequíveis, mas que devem contar com uma reflexão para que possamos dar início a um pensamento conjunto sobre esses pontos.

A primeira delas diz respeito à falta de comunicabilidade entre os diferentes programas. Dos Anjos sugeriu a criação de "comitês de orientação interdisciplinares", nos quais diferentes professores de diferentes programas pudessem cooperar na orientação desses alunos. Isso porque os programas estão recebendo alunos diferentes, cujos projetos não são aqueles que os professores esperam. O sistema atual, coloca o professor, "costuma transformar a diferença em erro, erro em reprovação e reprovação em exclusão". Uma das dificuldades seria, portanto, "em assumir que aquilo que muitas vezes é tratado como um erro é, na verdade, uma incompetência para lidar com a diferença". Esse reconhecimento permite que os orientadores peçam ajuda, que solicitem a colaboração de colegas de outros programas ou institutos para possibilitar a realização desses projetos que são, muitas vezes, baseados na biografia daquele aluno. Com isso, afirmou que seria possível receber as diferenças. O ponto crucial, porém, é um "olhar para dentro" e um reconhecimento, por parte dos próprios professores, de sua incompetência para orientar esses alunos.

Aqui o Dos Anjos levanta uma grande questão, que é a da transformação da diferença em um processo de aprendizado conjunto. Argumenta, portanto, contra aquilo que chama de "tolerância para com a diferença". Temos que superar este modelo de tolerância que vê a diferença como algo a ser moldado e trabalhado dentro dos pressupostos já existentes. Isso acarreta, muitas vezes, em uma visão da mesma como incompetência. É preciso que os professores reconheçam estas questões para que esses alunos não sejam levados a produzir dissertações iguais a dos outros, mas sim que tenham preservadas suas diferenças para que possam ter produções diferentes. Ou seja, não temos que "tolerar" a diferença, temos que desejá-la.

A segunda proposição, então, seria a de que o próprio processo seletivo seja um modo de lidar com a diferença de forma positiva. Os alunos devem entrar por um dossiê e suas biografias devem ser apreciadas e valoradas pelos programas. Pareceu evidente aqui, ao 
contrário do entendimento de alguns participantes da mesa, de que isso não significa uma rotulação ou estigmatização daqueles alunos afrodescendentes, indígenas ou com deficiência. Ao contrário, a proposta é justamente a de acolher esses alunos e apoiá-los de um modo diferenciado, como uma maneira de valorizar essa diferença. Os alunos que entram na universidade como optantes das ações afirmativas devem ser, segundo ele, reconhecidos como tal, para que, com isso, sua diferença seja apreendida pela instituição e por ela valorizada.

Além disso, destacou que as ações afirmativas devem ser um processo público, tratado abertamente. Isso para que fique claro que o que está em jogo é que as trajetórias escolares destes pós-graduandos são marcadas pelo racismo. Mais uma vez, ressalta Dos Anjos, "estamos falando de um reconhecimento e valorização da diferença para que seja possível lidar com ela de forma positiva".

Outro ponto importante é a flexibilização dos prazos impostos. E é essa a sua terceira proposição. Atentar-se para as diferenças é atentarse para as diferentes temporalidades de pesquisa, o que leva a uma relativização dos duros prazos acadêmicos impostos, em sua maioria, pelas agências avaliadoras. Logo, essa é uma proposta que exige não só um diálogo entre os programas de pós-graduação, mas também com as agências que avaliam esses programas. É necessário, portanto, um diálogo que perpasse as diferentes esferas para ressaltar a visão das ações afirmativas enquanto ações que enriquecem o programa. Enriquecimento este que virá a longo prazo. E esses alunos devem ser avaliados enquanto alunos que irão trazer esses efeitos para os programas.

Cabe ressaltar que, em um ambiente no qual o cumprimento rigoroso de prazos cada vez mais exíguos é fundamental para que se atinja uma boa pontuação imediata dos pós-graduações, estas questões devem ser tratadas com seriedade e clareza de posicionamento político. Deve-se trabalhar junto ao corpo docente e discente para que as diferentes epistemologias e temporalidades de alguns alunos optantes não sejam encaradas com demérito ou como algo prejudicial ao programa. Se estas questões não forem seriamente discutidas, a consequência poderia ser uma visão desses alunos enquanto 
incompetentes, o que, segundo Dos Anjos, "é pior do que não se ter ações afirmativas".

A quarta dimensão é especifica aos alunos afrodescendentes. Neste momento o professor lembra que "a diferenciação categorial deve ser a de negro e não de pardo ou preto. As universidades recebem alunos negros, e não alunos pretos e pardos", ressalta. É fundamental para a dinâmica que isso fique claro.

Gostaríamos de salientar que saber como nomear ou agir com outras pessoas pode parecer uma questão bastante simplória para as pessoas envolvidas com questões referentes às ações afirmativas e ao racismo, ou que trabalham com os "estudos da deficiência" ou "relações interétnicas", mas nos parece que para que as outras proposições façam sentido, necessitamos, sim, começar pelo mais básico: socializando conhecimentos, disseminando saberes e sensibilizando todo corpo institucional das universidades para a diferença.

Por último, Dos Anjos salientou que essa é uma questão que exige um comprometimento institucional, devendo ser encarado pelo Instituto como um todo e não somente pelos programas isoladamente. Ele destacou a necessidade de que seja construída uma frente institucional, para que essa problemática seja compartilhada e encarada coletivamente. Isso é importante, entre outros motivos, para a concessão de bolsas específicas para aqueles alunos que entram por ações afirmativas.

A breve e impactante fala do professor José Carlos dos Anjos deu tom para as falas subsequentes, principalmente ao destacar a incapacidade atual dos programas para lidar com as diferenças oriundas das ações afirmativas. Apontou para a importância de que esse seja um assunto tratado de forma pública e coletiva, pois, desta forma, será possível não apenas que os alunos optantes se beneficiem do ambiente acadêmico, mas que o ambiente acadêmico cresça a partir do alargamento de seu universo e da valorização destes alunos.

Após essa fala inicial, seguiram-se três relatos sobre a questão da inclusão de alunos com deficiência nos programas de pós-graduação. Ficou evidente neste evento o pouco espaço que as questões referentes à inclusão de pessoas com deficiência ocupa no meio acadêmico. A professora Dra. Liliana Passerino, do Pós-Graduação em Educação da UFRGS, apresentou a carência de um projeto institucional de 
acessibilidade e inclusão na universidade, a qual é evidenciada na total ausência de dados sobre o número de alunos com deficiência que já cursaram ou estão cursando uma graduação ou pós-graduação. Segundo a professora, o que sabemos é que o gargalo de acesso destas pessoas começa já no Ensino Fundamental. A professora apresentou dados que mostram que enquanto oitocentos mil alunos com deficiência frequentam escolas de ensino fundamental, apenas quarenta e oito mil estão matriculados no ensino médio. No ensino superior, estes números caem ainda mais: vinte nove mil alunos com deficiência estão no ensino superior, sendo que apenas nove mil em universidades públicas. "É por isso que não vemos esses alunos circulando pelos campus", concluiu a professora.

Isso faz com que a UFRGS, para ela, não seja a universidade número 1 do país, uma vez que deixa de fora toda uma importante parcela da população. Hoje, os alunos com deficiência entram na Universidade sem reserva de cotas. A professora lembrou da existência do "antigo projeto incluir" da Universidade, o qual pretende dar suporte para alunos com deficiência. No entanto, na prática esse órgão se mostra pouco efetivo, uma vez que, além de não dar conta da demanda por recursos para acessibilidade e outros materiais, o programa só é acionado quando o aluno ou algum professor individualmente o procura.

Uma das grandes ironias do próprio Programa Incluir é que as suas informações só são encontradas no site na Universidade, o qual, por sua vez, não é acessível (no sentido de não possibilitar a navegação de pessoas com baixa visão ou cegueira, por exemplo). "Todas as atividades que dependem do site e do portal do aluno - como o pedido de titulação, solicitação de matrícula, etc. - só podem ser feitas por uma pessoa que tem olhos, braços e ouvidos", ressalta a professora. Além disso, na UFRGS, não há qualquer relatório ou dados oficiais sobre o número de alunos com deficiência matriculados. Há, desde aí, um apagamento destes alunos, uma invisibilização da deficiência na universidade. Isso sem contar que hoje não temos mais o Programa Incluir, temos uma sala de acessibilidade que conta com uma funcionária que não é nem formada e nem tem capacitada para lidar com pessoas com deficiência.

Sua fala deixou claro que há muito pouco sendo feito institucionalmente em prol dos alunos com deficiência. Não só no que 
tange a sua entrada na universidade, mas também com relação a sua retenção. Em seguida, a professora trouxe o exemplo do PPGEdu/UFRGS, onde há linhas de pesquisa que são sensíveis à temática da inclusão. A primeira doutora cega e a primeira doutora surda do Rio Grande do Sul são oriundas destes programas. Aliás, esse acolhimento pelo PPGEdu faz com que haja mais alunos com deficiência na pós-graduação do que na Faculdade de Educação, onde há somente um aluno com deficiência atualmente. Segundo a professora, esta é uma informação importante, pois mostra que os alunos acabam optando por graduar-se em universidades que lhes proporcionem melhores condições de desenvolvimento e buscam a UFRGS somente no momento da pósgraduação.

A professora manifestou seu apoio para que as políticas de ações afirmativas incluam pessoas com deficiência não só na pós-graduação, mas também na graduação. Ainda que o processo seletivo do PPGEdu seja adaptado para esses alunos, isso é feito pelas linhas de pesquisas sensíveis a essa questão, sem que haja políticas institucionais mais amplas que busquem a inclusão e permanência das pessoas com deficiência. Isso seria fundamental para que se abra as portas da universidade para esses alunos. No entanto, Liliane destaca que essas ações afirmativas devem vir acompanhadas de medidas que possibilitem a permanência desses alunos em seus programas.

Nesse sentido, a professora afirmou ser importante que se definam mecanismos para acompanhamento e permanência e que os tempos e prazos da academia sejam flexibilizados em razão das diferentes necessidades destes alunos. Além disso, a inclusão pressupõe uma preparação física de acessibilidade de diferentes prédios e setores e de uma polarização da atenção a esses alunos, com a criação de núcleos em cada instituto e faculdade que responda por esses alunos e professores. Isso implica, também, um comprometimento financeiro com o custeio de bolsas de estudos e outros recursos para acessibilidade.

Um dos tantos pontos interessantes trazidos pela professora, no sentido de propor ações para a permanência de pessoas com deficiência na Universidade, seria a necessidade de uma preparação dos docentes para receber esses alunos. Com isso ela problematizou uma ideia que parece bastante comum no âmbito acadêmico de que pessoas com 
deficiência devam estudar sobre a deficiência. Ao contrário, acredita ela, "esses alunos devem, assim como todos os outros, serem livres para estudar o que quiserem, para ter a formação que desejarem".

A terceira fala da mesa coube ao Dr. Felipe Mianes, pessoa deficiente visual, historiador, doutor em educação pelo PPGEdu/UFRGS e atualmente cursando pós-doutorado na ULBRA. Felipe começou sua apresentação com um toque de humor: pediu desculpas, mas avisou que iria falar fora do microfone para que os ouvintes com alguma deficiência "intelectual" soubessem aonde ele estava e não ficassem olhando para as caixas de som, como ele mesmo tantas vezes fizera nas palestras que assistiu. O comentário provocou risadas pelo tom leve, mas ao mesmo tempo suscitou uma reflexão por parte daqueles que jamais haviam pensado sobre essa questão. Na sua primeira frase, Felipe já deixou clara uma das tantas dificuldades enfrentadas por um aluno com deficiência em um ambiente acadêmico pouco preparado para recebê-lo: "A cada vez que venho até o Campus do Vale eu me lembro o quanto é difícil chegar até aqui".

Um dos pontos principais de sua fala foi a necessidade de que a permanência das pessoas com deficiência seja fomentada e não somente o acesso à universidade. Nesse sentido, destacou a importância de que sejam dadas condições físicas de acessibilidade dentro dos diferentes campi, bem como que existam condições materiais diferenciadas e específicas para os diferentes alunos. "São coisas muito básicas... Por exemplo, um livro de 200 páginas em letra 12 e espaço um e meio para mim se transforma em um material impresso em letra 18 , em negrito, 0 que dá 600 páginas... Como vou trazer esse material para sala de aula? Um outro exemplo: no laboratório de informática tem apenas um computador com o leitor de texto que eu necessito. Quando chego lá ele está sendo usado. O que eu faço? Espero? Peço pra pessoa sair? [...] Pena que isso não tenha acontecido na UFRGS, porque quando entrei na graduação eu pedi o computador e quando me formei não tinham providenciado ainda".

Para ele um dos grandes méritos do Programa Incluir (que não existe mais) foi o fato de que, assim que entrou no programa, perguntaram a ele: "O que tu precisa?" Segundo Felipe, essa foi uma grande surpresa porque, até então, em toda sua vida, nunca lhe haviam 
feito essa pergunta e somente lhe davam o que achavam que seria necessário. Mas mesmo assim pouco pode contar com o Programa Incluir em seu tempo de graduação. Este programa atuava por demanda e nunca dava conta dos prazos.

Felipe questiona também se a falta de dados sobre os alunos com deficiência na UFRGS não seria, na verdade, o resultado de um apagamento destes alunos pela e na Universidade. Apagamento esse que se deve ao fato de "o atual Núcleo de Acessibilidade fazer política programas para alunos com deficiência e não com alunos com deficiência".

O desafio estaria, portanto, em construir um projeto de inclusão com as pessoas com deficiência, para que haja planejamento que busque manter esses alunos na universidade. Felipe chama a atenção para o fato positivo de estarmos tendo o espaço deste evento, mas que é necessário pensar o como vamos fazer a acessibilidade e a inclusão de pessoas com deficiência. "As políticas afirmativas podem e devem ser para pessoas com deficiência também". Já no final de sua fala, destacou que a questão da deficiência e da acessibilidade deve ser encarada como uma questão de todos, "afinal, ao envelhecermos, todos teremos que lidar com as dificuldades de acesso impostas pela vida. Um dia, segundo ele, todos seremos deficientes".

Um discurso diferente, mas igualmente politizado, foi trazido pelo próximo componente da mesa, o mestre Marcus Morais, pessoa com deficiência visual, professor de ensino fundamental e mestre pelo PPGEdu.

Marcus começa sua fala concordando com, mas complementando a fala de Felipe. Para ele, não seria uma questão de que um dia seremos todos deficientes, mas sim de que somos todos deficientes hoje, em razão de diferentes limitações que possuímos e enfrentamos em nosso dia a dia. "Acredito que ninguém tenha condições de se dizer perfeito, então somos todos deficiência neste sentido".

São várias as situações citadas por Marcus que relativizam o conceito de "deficiência", evidenciando "incapacidades" de seus colegas "normais" de trabalho, e questionando a "despolitização" da "deficiência" como uma questão individual. Um dia, conta ele, que frente a um 
computador sem acessibilidade em sua escola, o qual não tinha o programa de leitor de tela de que ele precisava para trabalhar, ele teve que pedir que uma secretária copiar um arquivo em seu pen-drive. "A secretária não sabia copiar um arquivo do computador no pen-drive. Daí ela chamou uma colega, que também não sabia! Quando foi que já estavam 3 pessoas em frente a um computador sem conseguir copiar um arquivo! Daí chamaram o estagiário e ele perguntou: 'Mas por que vocês não conseguiram?'. Há, é que o professor Marcus é 'deficiente'!”. Marcus ressalta que o menos deficiente era ele naquele momento: "A escola era deficiente por não permitir o acesso a todos àquele computador e meus colegas eram 'deficientes' por não dominarem uma ferramenta tão básica nos dias de hoje".

Marcus também levantou um questionamento sobre a fala do professor José Carlos, sobre necessidade de que a entrada pelo sistema de cotas fosse tornada pública. Segundo ele, isso faria com que os deficientes "andassem com esse cartaz" e perguntou: "Até que ponto isso inclui e até que ponto isso os separa dos "normais'?"

Durante toda sua fala Marcus destacou a importância de que seja criado um ambiente em que esse aluno com deficiência possa se sentir "dentro de uma normalidade", para que possa encarar a vida acadêmica em condições que lhe proporcionem a independência e a autonomia. Para ele, o fundamental é um ambiente em que a pessoa com deficiência possa aprender de forma autônoma. Já no vestibular, Marcus relata de forma cômica ter tido "acessibilidade" em seu ingresso na Universidade: "Eu fiz as provas do vestibular com um 'ledor' e um fiscal ao meu lado me olhando para ver se o ledor não ia me ajudar na prova. Aí vocês imaginam meu estado psicológico. Fiz prova de Física, Química e Matemática oralmente... vocês imaginem como é legal resolver questões matemáticas de matrizes nos dedos".

Marcus lembra que ter conseguido entrar na academia por este processo é válido, mas vê com preocupação o fato de ele ter tido que entrar com este estigma da deficiência, com um ledor e um fiscal ao seu lado. "Saber mentalmente mapas, abstrair todos os conhecimentos, não conta?", pergunta. As experiências de Marcus ilustram apenas um pouco das condições nada igualitárias às quais pessoas com baixa visão são submetidas diariamente. Uma tecnologia poderia ter evitado que ele 
passasse por este processo todo. Quem, afinal, contou com "privilégios" na hora de competir por uma vaga na universidade? Se há alguma meritocracia, esta seria inversa neste momento.

Marcus finaliza novamente expondo sua opinião de que a discussão deve ser pública, esse é um espaço para isso, mas não o processo. "Como fica o Marcus, a pessoa Marcus, ao caminhar pelo campus com um crachá 'eu sou deficiente', 'eu sou cotista'? É interessante”, diz ele, "que após eu ter feito toda uma graduação e um mestrado eu não saiba nada sobre políticas afirmativas para pessoas com deficiência na UFRGS. Se tem, me apresentem [...] O que eu conheço são 'pessoas afirmativas' e poucas ações".

Já no mestrado, Marcus conta ter tido "a sensação de sentir-se em uma normalidade. Não normal, porque ninguém é, mas numa normalidade". Isso foi quando a professora Liliana criticava seus textos e o mandava refazer dentro das possibilidades que ele tinha para tanto. Segundo Marcus, "o acesso deve ser possibilitado. As cotas devem ser possibilitadoras do acesso e da permanência neste espaço. Mas com muito cuidado para que estas políticas afirmativas não sejam confundidas com políticas de caridade. Afinal, diferentes todos somos, mas trazer 0 rótulo da diferença é complicado... todos me perguntam: 'Como tu fez aquilo ou isso?' E eu costumo responder que as melhores coisas a gente faz ou no escuro ou de olhos fechados [risos]".

As manifestações da plateia que seguiram as falas da mesa contaram com a participação de Eliane, doutoranda em Educação; Jorge Amaro, doutorando do curso de Políticas Públicas da UFRGS; Valéria Aydos, doutoranda do PPGAS-UFRGS; Patrice Schuch, Coordenadora do Programa de Pós-Graduação em Antropologia da UFRGS; Karen Bruck, da Coordenadoria de Acompanhamento do Programada de Ações Afirmativas (CAF); Zaqueu Claudino, mestre em Educação pelo PPGEdu; e prof. Sergio Batista, do PPGAS.

Eliane compõe a comissão de ações afirmativas do PPGEdu e ressalta que o grupo está aberto a incorporar outros colegas indígenas e com deficiência. Afirma que como negra não pode falar em nome dos indígenas e das pessoas com deficiência. 
Jorge Amaro menciona algumas experiências de outras universidades e pós-graduações e alerta que "a questão das cotas é um debate político necessário e doloroso". Afirma que "no Estatuto das Pessoas com Deficiência, aprovado recentemente, o artigo que foi vetado foi justamente que previa cotas para pessoas com deficiência nos cursos técnicos e nas universidades. A lei máxima das pessoas com deficiência exclui a pessoa com deficiência! Então, o meio acadêmico é um espaço onde deveremos estar. Como diz o lema: 'Nada sobre nós sem nós'”.

Valéria menciona que devemos valorizar não apenas saberes diferentes, mas formas diferentes de aprender, e lembra que existem "deficiências não visíveis" e outras especificidades que devem ser levadas em conta. Compartilha também que muitas das experiências de inclusão de pessoas no mercado de trabalho, para além das posturas políticas ou mercadológicas com relação às cotas, têm demonstrado que existe muita desinformação e insegurança, por parte de colegas e gestores, sobre como tratar as pessoas com deficiência.

Patrice Schuch, enquanto Coordenadora do Programa de PósGraduação em Antropologia, parabeniza as mesas e ressalta algumas das dimensões que envolvem a implementação de cotas nos programas de pós-graduação, incluindo o acesso e o acompanhamento destes alunos ao longo dos cursos. Devemos realizar não apenas um trabalho técnico, mas político de encararmos estas políticas como um ganho para os programas. Acredita que, enquanto UFRGS, os participantes podem fazer uma moção de incentivo de ações afirmativas junto à PROPG, já que vários programas estão ali contemplados, como a Sociologia, História e Educação.

Karen informa que a CAF está trabalhando no desenvolvimento de novas metodologias tanto para capacitação de alunos, professores e funcionários quanto para gestão do próprio programa. Espera que todos possam se manter em contato para que este trabalho seja o mais integrado possível.

Zaqueu pergunta como está sendo observada a questão da Casa do Estudante no que se refere às vagas para alunos indígenas. "O que está acontecendo com nossos alunos, que estão indo para casa e não estão retornando?" Ele preocupa-se com as condições atuais de permanência dos alunos indígenas na universidade e critica a forma como o 
acompanhamento pedagógico tem sido feito. "Não adianta eleger um aluno para ser um monitor do indígena por um semestre. Essas pessoas têm que ser capacitadas para fazer esse acompanhamento e devem permanecer com o indígena durante todo o curso". "Devemos fazer com que a universidade se adeque aos indígenas, e não os indígenas à universidade".

O prof. Sergio Batista agradece a todos os presentes, principalmente os colegas que vieram de longe, menciona que a Comissão de Ações Afirmativas do PPGAS vem se debruçando sobre essas questões há algum tempo e que hoje essa conversa veio a somar para todos. Finaliza a manhã de debates agradecendo a todos e lançando o desafio que o debate seja efetivado em ações pragmáticas e institucionais. "Praticamente, que mecanismos são esses que estão marcando as experiências diversas relatadas aqui e que devem ser levados em consideração para implementação das cotas? Que pensemos como valorizar as especificidades e que cada professor possa pensar que línguas, que conteúdos vai trabalhar; que cada estudante possa pensar sobre suas relações com o 'outro' e assim vai". E salienta "que também nós, professores e alunos, não percamos nossas especificidades, nossas linhas de pesquisa... que possamos construir isso juntos".

A prof. ${ }^{a}$ Marcela, da UnB, finaliza a manhã com uma manifestação emocionada, dizendo que "sai do evento com uma energia que estava perdendo nestes tempos difíceis" e convida a todos e todas para um próximo evento em Brasília, nestes mesmos moldes!

Ao finalizarmos esta relatoria, gostaríamos de registrar também que a invisibilidade das pessoas com deficiência, relatada pela professora Liliana, não se dá exclusivamente no ensino superior. Segundo depoimentos de militantes com deficiência, esta parcela da população foi até muito pouco tempo o "etecetera" dos movimentos sociais para os estudos acadêmicos. Apesar de, como lembra Boaventura de Souza Santos (2001), o "novo movimento transnacional de direitos" do final do século XX ter inaugurado um espaço de disputas simbólicas pela inclusão social de grupos minoritários a partir da construção de um novo modelo de relações e de justiça baseado não apenas nos princípios da redistribuição (igualdade econômica), mas também do reconhecimento 
(diversidade cultural) de sua condição destes grupos como minoria social que sofreria discriminação, a "discriminação por deficiência" conta ainda com pouco espaço de debate político frente a diferenças de etnia/raça ou gênero.

Segundo Diniz e Santos (2010), tal invisibilidade deve-se, em parte, ao fato de o debate ter-se calcado numa concepção biomédica da deficiência como "corpos e mentes em desvantagem" e, também, por conta da exclusão social destas pessoas, causadas em grande parte por ambientes sociais restritivos à participação plena, ter sido historicamente traduzida em termos de azar ou tragédia pessoal.

Gostaríamos também de enfatizar, a partir da fala da professora Liliana e dos relatos de Bruno e Marcus, para a necessidade de repensarmos a despolitização com a qual a questão da acessibilidade vem sendo vista em nossa sociedade e, também, de refletirmos sobre a deficiência como mais uma diversidade humana.

\section{Referências bibliográficas}

DINIZ, Débora; SANTOS, Wederson. Deficiência e Direitos Humanos: Desafios e Respostas à Discriminação. In: DINIZ, Débora; SANTOS, Wederson (Orgs).

Deficiência e discriminação. Brasília: Letras Livres; UnB, 2010. p. 10-19.

SOUSA SANTOS, Boaventura de. Nuestra America: Reinventing a Subaltern Paradigm of Recognition and Redistribution. Theory, Culture \& Society, v. 18, n. 2-3, p. 185217, 2001. Disponível em: 〈http://tcs.sagepub.com/content/18/2-3/185>. Acesso em: 10 set. 2012.

Recebido em: 14/11/2015 * Aprovado em: 14/12/2015* Publicado em: 31/12/2015 